1)r. Wm. D. Granger, for eight years first assistant phy . sician at the State Asylum for the Insane, at Buffalo, N. Y. opens a private institution for the insane at Mt. Vernon, near this city, on June ist. I)r. Granger has created for himself not only a State, but a national reputation, through the important part he took in aiding I)r. J. B. Andrews to make the Buffalo asylum the model institution of this country, and by the wide dissemination of his "Handbook for "lraining Nurses upon the Insane," published some years agro by G. l'. I'utnam's Solss. He has purchased the Masterson estate, midway between Mit. Vernon and Bronxville, consisting of an elegant stone mansion, cottages and serenteen acres of beautiful grounds upon the high ridgre between the two towns. This institution will be the nearest to the city and most convenient of reach among those now in existence.

\title{
Ileur Tustruments.
}

\section{AN, IMIROVED CAIORIMETHER.}

By ISAAC: OTT, .H. I.

$\mathrm{T}$ HE great importance of the study of the heat production and heat dissipation of animals has made it necessary to perfect the heat-measuring instrument, usually called a calorimeter. This instrument may be either an air or water calorimeter. Without going into any historical cletails, it is permissible to state that Rosenthal and Rubner have recently constructed two air calorimeters, which are held to be quite reliable. I3ut as they require greater care in the management of them than water calorimeters, the latter have been extensively used. Of the water calorimeters, the old one of Despret\%, and Du Long, and that of d'Arsonval, are the most important. In the Despretz and Du Long instrument the interior box of metal is submerged in the water, and through the water a serpentine coil runs to convey air to and from the inner box containing the animal. It is in the main the instrument that has been used in Germany and this country. D'Arsonval wits the first to make the interior box immovable by fastening it to the outer wall of the water resevoir. He also made a door to close the opening into the animal chamber. It was an improvemement upon the clumsy, time-wasting and inaccurate instrument of Du L.ong. It kept the temperature constant by means of the expansion and contraction of the mass of water regulating a gas burner. Whatever change of temperature in the animal must then be due to changes in the 
tissues. It also had a serpentine coil for removing the air from the enclosure. I have used this calorimeter of d'Arsonval's, but in a manner not intended by its originator. The gas arrangement was dispensed with, and it was managed as other water calorimeters. Reichert has also constructed a calorimeter where the interior box is arranged in an immovable manner by attaching its inner reservoir to the outer wall of the water chamber.

That the animal may be quickly placed in the interior of the instrument he has inserted a pluss into an opening of the instrument, in the place of a cloor. Otherwise it is essentially the instrument of Du Long. 'The error of Reichert's calorimeter is 8.75 per cent. In the improved calorimeter Fin. I) I have taken the cylinder form of d'Arsonval and made

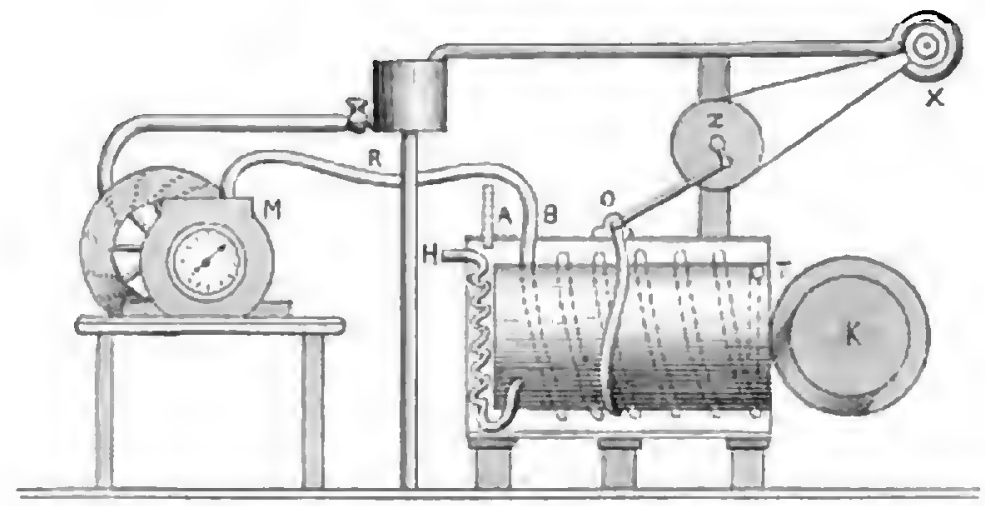

several modifications. The agitator, "sits astricle the inner cylincler, outsicle the leaden coils, and is run at the rate of sixty to seventy times a minute by means of a water motor, $x$. In other calorimeters, the water is occissionally agritated by a hand contrivance. Instead of the air entering the inner chamber in a straight tube, it traverses the tube $I I$, coiled upon itself in the water reservoir of the instrument, and enters the enclosure at its base. The air emereres at the opening $\%$ at the top, and is carried out through the serpentine coil and through the aspirating meter.$/$, which records at the same time the amount of air. The constant activity of the agritator caluses the water to equally diffuse the heat and to permit none to be siven to the air. In the instrument of Reichet, nearly one-sixth of the heat is given to the air, and like all air calculations this is conducive to error. The door $K$, swings upon a hinge, and in its centre has a glass by which one can readily see the state of the animal or the apparatus connected with it. At its edge it is lined 
with rubber and closed by powerful iron screw clamps. In front of the door is a mattress of saw-dust several inches thick. Over and around the calorimeter, instead of the usual saw-dust or felt, I used the packing material of wood fibre known as "Excelsior." The whole is enclosed in a square box, which has a door. The calorimeter is sixteen inches in length and twelve inches in diameter. At $A$ is a circular opening, through which a thermometer, gracluated to $\therefore$ of a degree Fahrenheit, passes into the water and enables one to easily read a hundredths of a degree. At $B$ is an opening in the air tube for the air thermometer to be pushed in.

The calorimeter is made up of the following parts: water, 30.72 lbs.; iron, 17 lbs.; solcler, I.50 lbs.; lead, 5 I lbs. 13y. multiplying these with their "specific heats," there is obtained the number 34.32 .

IVater, 30.72 lbs.

lron, 17.00 "

Solder, 1.50 "

L.end, 51.00 "
Sip. heat.

\begin{tabular}{|c|c|c|}
\hline 1.00 & $=-$ & 30.72 \\
\hline .1138 & $\because$ & 1.9346 \\
\hline .0780 & 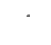 & 0.118 .3 \\
\hline .03050 & & 1.5555 \\
\hline
\end{tabular}

34.3284

34.32 units of heat necessary to raise the calorimeter ${ }^{j} \mathrm{~F}$.

To test the instrument as to its accuracy, I used a tin vessel, closed on all sicles except a small opening for the introduction of a thermometer and the heated water. This opening is closed by a metal screw-cap. When the weight and temperature of the water in this test-vessel are known, it is put in the calorimeter, and air aspirated through the calorimeter. Below is an experiment showing the method.

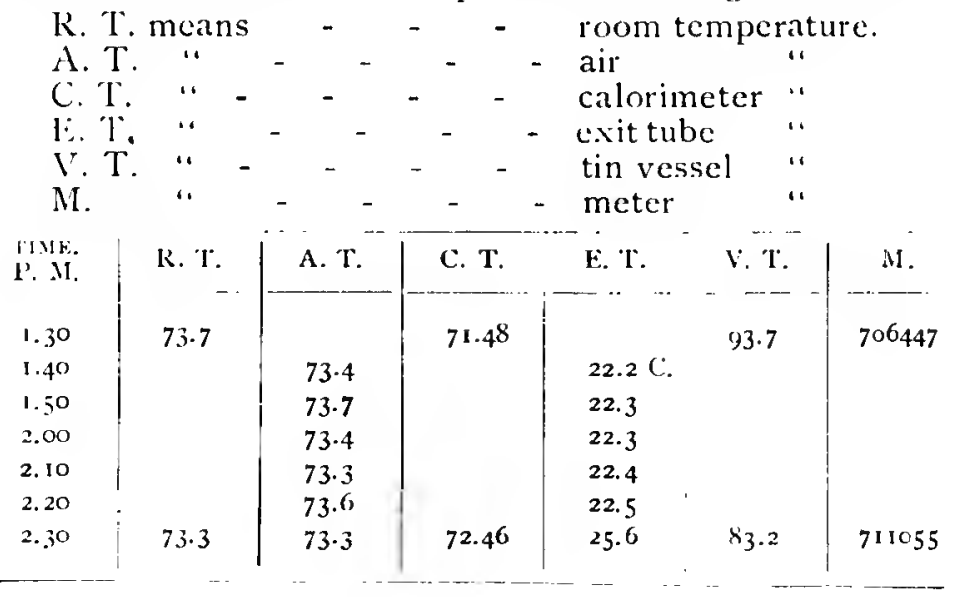


BOOK RETLEUS.

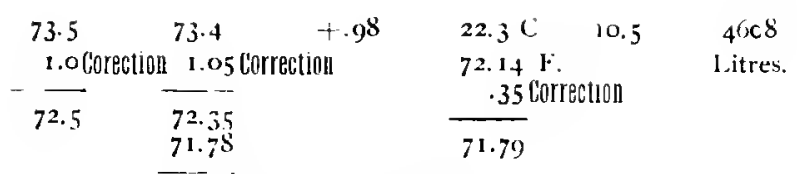

.56 loss of temije al air.

IVeright of tin vesiel and water 4.42. IIs.

Weight of tin ressel

1. 3

Water $\quad 312$

Heat lost ly ressel of water -33.85

Heat accounted for by calorimeter $=-32.02$

lirror 5.4 "..

As is seen by the calculations the error is $5.4 "$ ". I performed a half do\%en experiments, and found the variations from this number to be within a degree; hence, it is necessary to assume that it is an instrument of precision. For absolute accuracy the moisture of the air and the barometic correction should have been made. but they "rould not alter the result perceptibly. It "ias alwa's used with the air a degree or so above the temperature of the ealorimeter. The agitator was also set in motion for a half lour before the observation eommenced. The room temperature for twenty-four hours previously was kept nearly the same. With these precautions the instrument works aceurately. This instrument has been used durings the past year in my laboratory:

\section{Tilonli Ineniems.}

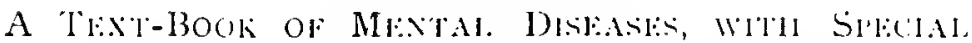

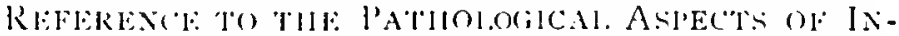
sinllY. By IV. Beran Lewis, I..R.C.P. Philadelphia : 1'. Blakiston, Son \& Co., I\$go.

We most cordially welcome Dr. Lewis hook. It treats of mental diseases from an elevated and new aspect, and bears ihroughout the stamp of research and originality; and it is of especial value, as it contains as well the product of years of practical experience.

It is refreshing to find no quarreling over classifications, defin tions of insanity, clinical romancing, or medico-legal inanities. It begins ly a careful detail of the anatomical structure of the nervous system, esipecial attention being given to the cerebral cortex and the nerve-cells.

Here and there throughout this first section the author directs the reader to the most important histological elements that play so important a role in the prathological changes of certinin furms of insanity. 